\title{
EXPERIMENTAL INVESTIGATION OF DOUBLE-PASS SOLAR AIR HEATER
}

\begin{tabular}{|c|c|}
\hline CHANDRA BHUSHAN & S.N Singh \\
Department of Mechanical Engineering & Associate Professor \\
Indian School of Mines & Mechanical Engineering Dhanbad, Indian \\
Dhanbad, India & School of Mines \\
Cbhushan1992@gmail.com & Dhanbad, India \\
\hline
\end{tabular}

\begin{abstract}
To investigate the experimental analysis of the thermal performance of the double pass solar air heater having a collector angle of inclination $60^{\circ}$ and there is a double flow channel. Solar air heater efficiency can be affected by various parameters such as collector length, type of absorber plate, mass flow rate of air, inlet temperature and air velocity . It is a special type of heat exchanger which transfers heat energy, it is obtained by absorbing solar radiation in the air, and basically in heat exchanger heat transfer of fluid to fluid occurs by conduction and convection processes. The losses through the bottom and side of the heater are reduced or almost eliminated by using the insulation. An important application of solar air heater is to supply hot air for agricultural product and for heating of space.
\end{abstract}

Keywords-Two pass solar air heater, Thermal efficiency, mass flow rate of air, absorber plate.

\section{INTRODUCTION}

Solar air heater(SAH) is the simplest form of flat plate solar collector in which the working medium is air.The principle usually followed is to expose a dark surface to solar radiation,so that radiation is absorbed.A flat plate collector used for heating the air generally know as a solar air heater.A solar air heater is a special type of heat exchanger that transforms solar radiation energy into internal energy of the transport medium air.There are twotypes of plate solar collector, water heating solar collector and air heating solar collector.TheSolar air heater is less complicated as compared to solar water heater because it has free from corrosion and freezing.

A solar air heater is a device, which convert solar radiation into the heat energy.This device is simple and can be constructed with less expenditure. Solar air heater made up of a wooden,galvanized irons hot,FRP/GRP material.Absorber plate is coated with black paint to absorb maximum solar radiation and clear glass cover provided to the top to allow maximum solar radiation inside inclination,provided with the solar air heater for the maximum radiation receive during the day period.Insulation of glass wool,thermocol,wooden plate,asbestos etc.

SAH may be divided into two main categories. The first category is related to the air channel flow configuration.To increase the system efficiency various air channel flow configurations will be constructed.The various configurations may be expressed in four subtitles under this category. Single flow,single pass, double flow single pass,single flow double pass and single flow recycled double pass. The second category is related to the air channel design. The air channel design affects the system efficiency significantly. For that reason different design, configuration can be used in solar collectors.The second category can also be expressed in three sub-categories such as;flat plate, extended surface assisted,porous media assisted.

Applications of solar air heater are such as the solar air heating system can be used in many industrial activities drying, heating like as chemical, pharmaceutical, bulk drug, limited area of textiles and it is used in cloth drying, fish drying, chillingdrying, coffee beans drying and also used in vegetable fruit dehydration. Ventilation, fresh air or makeup air is required in most commercial, industrial and institutional building to meet code requirements. By drying air through a properly designed unglazed transpired air collector or an air heater the solar heated fresh air can reduce the heating load during daytime operation.

Advantages of SAH are such as- solar collector does not pollute. It avoids carbon dioxide, nitrogen oxides, Sulphur dioxide. It is typically the most cost-effective out of all the solar technologies, especially in commercial and industrial applications. 
Asia Pacific Journals

\section{2- SET-UP CONFIGURATION}

\section{1-Technical specification}

Dimension of plywood $=2 \mathrm{~m} \times 1 \mathrm{~m}$

Thickness of plywood used $=12.5 \mathrm{~mm}$

Thickness of the glass $=3 \mathrm{~mm}$

Digital hot wire anemometer

measuring range $=1-50 \mathrm{~m} / \mathrm{sec}$

\section{2-Experimental set-up}

The experimental setup is shown in figure has been used to estimate the mass flow rate and efficiency of the flat plate air heater under varying conditions.Plywood is used for making the frame of solar collector in cubical shape of $5 \mathrm{~mm}$ thickness. The internal dimension of cuboidal shape $2 \mathrm{~m} \times 1 \mathrm{~m} \times 0.1 \mathrm{~m}$. The inclination angle of the collector was $60^{\circ}$ from horizontal and glazed glass cover sheet is used. In this setup the orifice plate of $4 \mathrm{~cm}$ diameter and simple manometer is used, itconsists of a glass tube bent in U-shape. The manometer also had a graduated scale( $1 \mathrm{~mm}$ least count) for measuring the difference in liquid levels.Air is circulated by radial fan, which was powered by electricity and flow between the absorber plate and glass cover. Air rate was adjusted by blower regulator for different speed. A Test was conducted between 9:00to 15:00pm in day time. The absorber was of the a plate absorption coefficient $\alpha=0.95$.

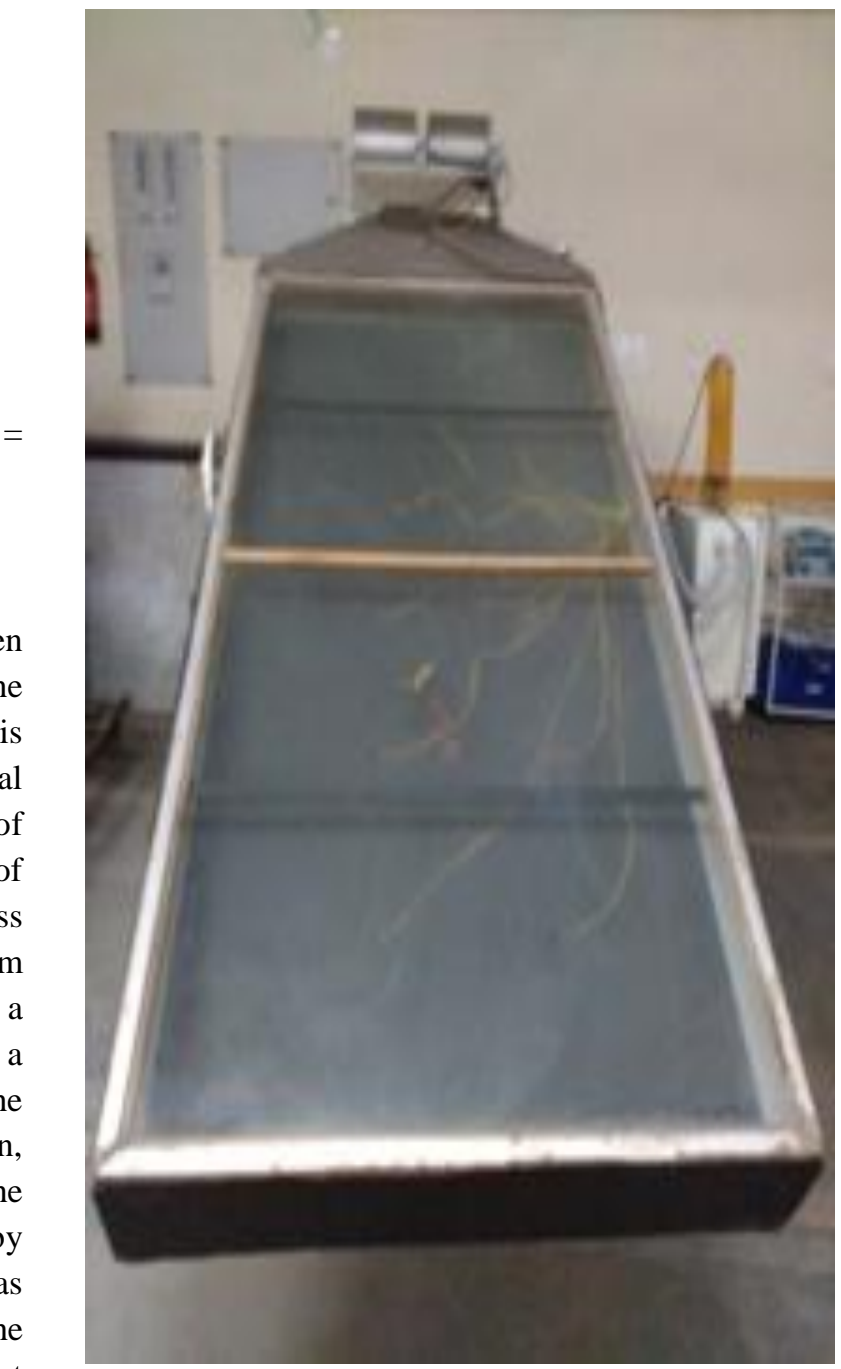

Figure:1 Double -Pass Solar Air Heater

\section{3-MATHEMATICAL FORMULATION}

\section{1- Efficiency of collector}

The efficiency of a solar collector is defined as the useful gain energy to the incident solar energy, that is.

$$
\mathrm{\eta}=\frac{\text { Useful gain energy }}{\text { Incident solar energy }}
$$


Asia Pacific Journals

\section{2-Useful gain energy}

$Q u=\dot{\mathrm{m}} \mathrm{Cp} \Delta \mathrm{T}=\dot{\mathrm{m}} \mathrm{Cp}(\mathrm{Tout}-\mathrm{Tin})$

3.3- Mass flow rate

$\dot{\mathrm{m}}=\rho \mathrm{V}=\rho \cdot \frac{\pi d^{n_{2}}}{4} \mathrm{x}=Q \cdot \rho$

3.4- Discharge measurement

$Q=C d A \sqrt{2 g h}$

\section{5-Reynold number}

$(\mathrm{Re})=\frac{\rho \mathrm{VDe}}{\mu}$

Where, Hydraulic diameter $\left(D_{e}\right)=\frac{4 W H}{2(W+H]}$

\section{6-Nusselt number}

$(\mathrm{Nu})=0.0158 \mathrm{Re}^{0.8}$

\section{7-Fraction factor}

(f) $=0.079 \mathrm{Re}^{-0.25}$

\section{4-RESULTS \& DISCUSSIONS}

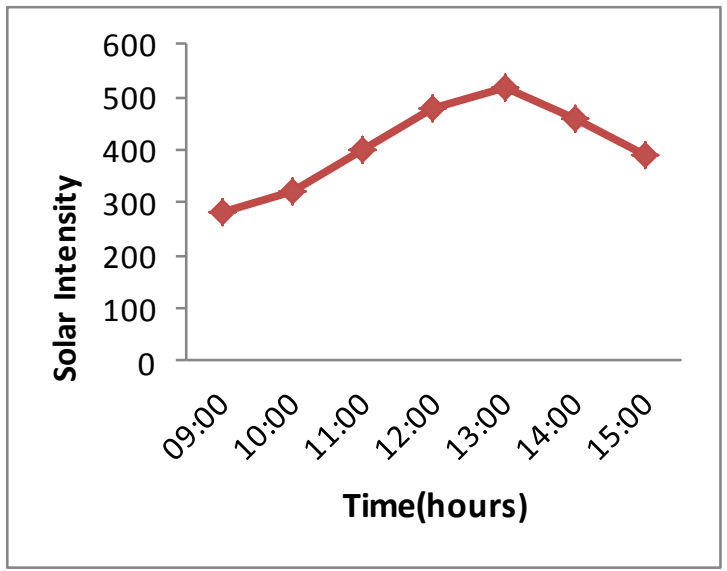

Figure-2 Variation between time and solar intensity.
ISBN: 978-81-930411-8-5

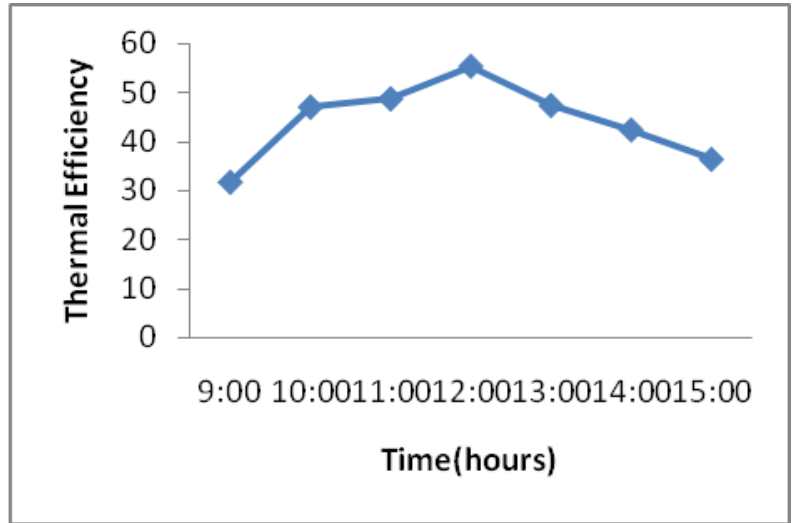

Figure-3 Variation between time and thermal Efficiency

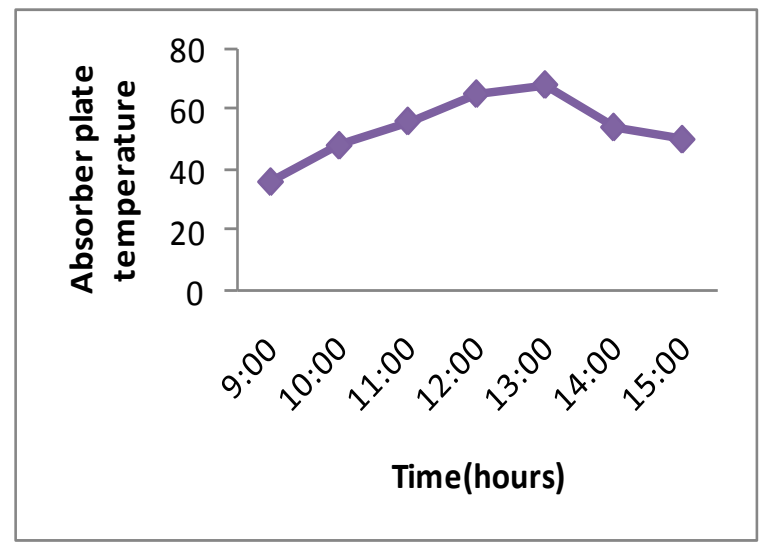

Figure- 4 Variation between time and absorber plate temperature.

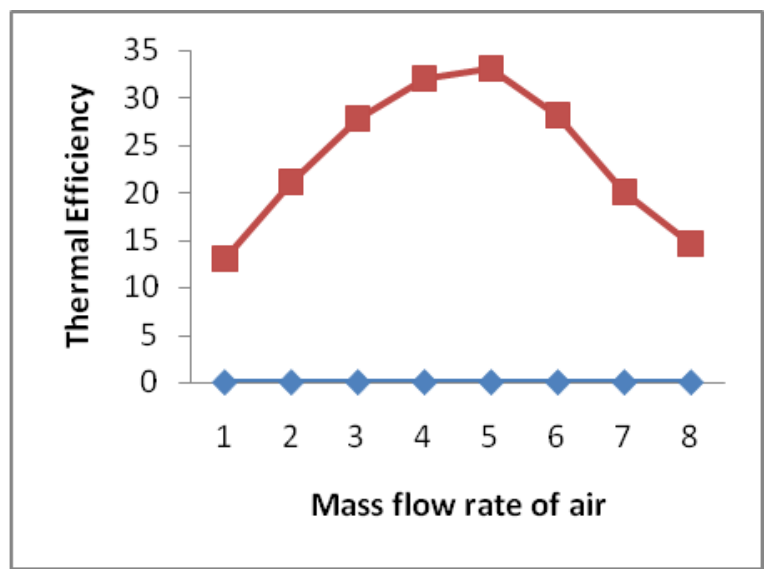

Figure-5 Variation between mass flow rate increases and efficiency. 


\section{ELK Asia Pacific Journals - Special Issue \\ ISBN: 978-81-930411-8-5}

Asia Pacific Journals

Due to use of constant air flow thrown by the blower, mass flow rate remains constant and due to it, uniform temperature rise occurs inside the solar air heater consist of the absorber plate. It has good heat transfer coefficient, hence the temperature rise will occur, this is the main reasons for increasing the temperature of the absorber plate inside the solar air heater. Fig 2 shows the variation between time verses solar intensity. It shows that, when time goes, solar intensity increases from morning 9 am to evening $15 \mathrm{pm}$ and highest at 13:00 pm then gradually decrease. Solar intensity is also playing an important role in solar air heater. Because when air come in contact with solar intensity, hence due to natural convection process, the temperature of the air increases. Fig 3 shows the variation between time and Thermal efficiency. Thermal efficiency is also playing a vital role in the performance of solar air heater. Because it is nothing but the ratio of work done per heat supplied in the form of solar intensity as well as a blower. Hence, it is seen that thermal efficiency gradually increases from morning to evening because it depends on solar intensity. It is lowest at morning 9 am and highest at 13:00 pm and then it gradually decreases. Highest thermal efficiencies achieved at 13:00 pm and it was more than 55 percent. Fig- 4 show that, when time is increased then solar radiation intensity increases this result is obtained by using pyrenometer device. Fig-5 is showing that when The mass flow rate of air increased at a certain limit so thermal efficiency increases, then after that decreases because the mass flow rate of air have good turbulent flow of air is obtained in the flow channel of the collector.

\section{5-CONCLUSION}

Detailed experiment study on double-pass solar air heater can show the following points:

- The thermal efficiency of solar air heater greatly depends on time, solar intensity, mass flow rate of air.

- Solar air heater having the thermal efficiency of varying from 0.23 to 0.58 during morning $9 \mathrm{am}$ to $1 \mathrm{pm}$ then it's gradually decreases.

- Solar air heater absorber plate temperature increases with increases solar intensity when the mass flow rate of air constant.
- During experimental analysis we have seen that outlet temperature increases with increase solar intensity as well as increases time from morning to evening.

\section{6-REFERENCES}

[1] Prasad et.al 1983"Heat transfer characteristics of a solar air heater used for drying purposes" Appl.Energy 8393.

[2] Choudhury (1999)"Performance and cost Analysis of two pass solar air heater" Elsevier science Ltd.

[3] Bashriaet.al(2007) "Analysis of single and double pass v-Grooves solar collector with and without porous media" International journal of Energy and Management issue 2 volume 136.

[4] Foudholi et al.(2011) "Analytical and Experimental studies on thermal efficiency of the double pass solar air collector with finned absorber" American journal of Applied Science vol 8pp 716-723.

[5] Kumar et.al(2012) "Experimental investigation of solar air heater using porous medium" IJMET PP 387-396

[6] Gonzalez et.al (2012) "Thermal evaluation and modeling of double-pass solar collector for air heating" International conference, limt\&need Towered an envirmental responsible architecture lima pp$7-9$.

[7] Fouedchabane et.al(2013) "Thermal efficiency Analysis of a single Flow solar air heater with different mass flow rate in a smooth plate" Frontier in heat and mass transfer.

[8] Gaur et.al. "An experimental investigation of a novel design of double pass solar air heater" International journal of chem. Tech Research vol.5pp1036-1040.

[9] Sukhadiya et.al."'Experimental investigation of double pass solar air heater with different arrangement using aluminum material.".IIT Gandhinagar,Gujarat, India.

[10] Budea( 2014) “ Solar air collector for space heating and ventilation-performance and case studies in Romania climatic conditions." University Politechnics of Bucharest, Power engineering faculty,040 0214029865 .

[10] S.Satchunanathan and Deonaine, Atwo pass solar air heater. Solar energy 15,41

[11] Thombre,sukhatme,1995. Turbulent flow heat transfer and friction factor characterristics of shrouded fin arrays with uninterrupted fins. Experimental thermal and fluid science,10,388.

[12] Singh, Performance studies on continuous longitudinal fins solar air heater.Proceedings of the $1^{\text {st }}$ national conference on Advances in energy research,IIT Bombay,205-210. 


\section{Asia Pacific Journals}

[13] Mahmood and Aldabbagh," Double pass solar air heater with transvers fins and without absorber plate". World academy of science, engineering and technology, Vol:2013-06-23.

[14]Fraisse et.al.The use of a heavy internal wall with a ventilated air gap to store solar energy and improve summer comfort in timber frame houses.Energy Build 2006,38,293-302.

[15] Ben Slam R et.al "Air solar collector with baffles Aerodynamics, heat transfer and efficiency 'RERIC' "International energy journal" vol 18 . 